\title{
EXPERIMENTAL INDUCTION OF ERYTHEMA NODOSUM ${ }^{1}$
}

\author{
By ALVIN F. COBURN AND LUCILE V. MOORE \\ (From the Department of Medicine, College of Physicions and Surgeons, Columbia University, \\ and the Presbyterian Hospital, New York City)
}

(Received for publication May 25, 1936)

The syndrome of erythema nodosum is known to occur in association with a number of diseases (1). The erythematous nodules are strikingly similar both in their gross and microscopic appearance, irrespective of the infection with which they are associated. This similarity of appearance suggests that the lesions may result from a common underlying mechanism. The nature of this mechanism is unknown. However, it has been pointed out that patients with erythema nodosum manifest an unusually intense skin reactivity to products of the bacterial agents responsible for their infection $(2,3)$. Whether this phenomenon has any significance in the development of the lesions remains to be determined. The present report deals with experimental observations which throw some light on the relationship between intense skin reactions to specific bacterial protein and the development of this syndrome.

Twenty-two patients with erythema nodosum have been under our observation in the past ten years. Two of these individuals had x-ray evidence of pulmonary tuberculosis, reacted strongly to tuberculin, were negative to hemolytic streptococcus nucleoprotein and had normal antistreptolysin titers (33 units on repeated determinations). The other 20 patients reacted strongly to hemolytic streptococcus nucleoprotein, weakly or not at all to tuberculin and had elevated antistreptolysin titers varying from 125 to 2500 units with a median of 500 units. Twelve patients who have been studied in detail are the subject of the present paper.

Subjects selected. Eleven girls or young women and one boy ${ }^{2}$ were selected for special study. All had high antistreptolysin titers, ranging from 250 to 2,500 units with a median of

\footnotetext{
1 The work reported in this communication was carried out under the W. K. Kellogg Foundation Fund.

2 This sex distribution is characteristic of the incidence of erythema nodosum, both in our group and that reported by Edström (1).
}

500 units. All had recent or subsiding erythema nodosum on both legs, symmetrically distributed.

Procedure. All were given hemolytic streptococcus nucleoprotein fraction C $19 \mathrm{~K}$ (ref. 2, page 228), intracutaneously on the volar surface of the forearm. Some were given, in addition, nucleoprotein of hemolytic staphylococcus, Pneumococcus I, Pfeiffer bacillus and $B$. catarrhalis. All doses were standardized to contain $.001 \mathrm{mgm}$. nitrogen.

RESULTS

Primary reactions. All subjects developed severe local inflammatory reactions to the nucleoprotein of hemolytic streptococcus, weak or negative reactions to the other bacterial proteins. These reactions began in 12 hours, were intense in 24 hours, reached their height in 48 hours and began to subside in 72 hours. Scaling and induration followed and persisted for a number of days.

Secondary reactions. Six of the 12 individuals developed a recrudescence of erythema nodosum following the skin test. The recrudescence began in each instance 36 hours after the skin test; that is, about 24 hours after the beginning of the inflammatory reaction at the site of inoculation. The nodules persisted for 24 to 72 hours and were entirely gone by the time that the inflammatory reaction on the arm had subsided. Nodules on the lower part of the legs appeared first and subsided last. None of the induced recrudescences were as severe as the original attacks.

It was possible to repeat these artificially induced attacks a second time on each subject, by a new injection of fraction $\mathrm{C} 19 \mathrm{~K}$ on the other arm. The second injection of $\mathrm{C} 19 \mathrm{~K}$ did not cause the original site of injection to flare up in a single instance. General skin reactivity to $\mathrm{C}$ $19 \mathrm{~K}$ was undiminished in these patients after six months, and was still present at the end of one year. However, after a period of two or three weeks it was no longer possible to induce 
a recrudescence of erythema nodosum on the legs. Two illustrative case histories are presented.

\section{Mary M., History Number 278407}

The patient, an 8 year old girl of Irish-American parentage, was admitted to the hospital with erythema nodosum of two weeks' duration. Her father had had rheumatic fever, and she had had erythema nodosum at the age of five. Her history was free of frank rheumatic manifestations. On physical examination mild pyrexia, tachycardia and fading erythema nodosum over the lower anterior third of each tibia were present.

Laboratory findings. X-ray of chest was negative; $\mathbf{x}$-ray of sinuses showed multiple sinusitis; throat culture showed no hemolytic streptococci; white blood count was 12,000 and blood sedimentation rate $55 \mathrm{~mm}$. in 1 hour; antistreptolysin titer was 500 units on repeated determinations; Mantoux and Dick tests were negative.

The left maxillary sinus was irrigated just before the patient's discharge from the hospital. The throat culture at this time contained no hemolytic streptococci; material from the sinus, however, contained beta hemolytic streptococcus Type XIII in almost pure culture.

Skin test. Primary reaction. Three days after admission, when it was seen that no new lesions had appeared on the legs, the patient was given an intracutaneous test with $0.1 \mathrm{cc}$. of hemolytic streptococcus nucleoprotein fraction $\mathrm{C} 19 \mathrm{~K}$ (containing $0.01 \mathrm{mgm}$. nitrogen per cc.). The reaction to this test at 24 hours was $8 \mathrm{~cm}$. $\times 4.5 \mathrm{~cm}$., erythematous, indurated, hot, extremely painful with a vesicular center. The skin test was repeated seven days later and a similar reaction occurred, measuring $9 \mathrm{~cm} . \times 7$ cm.

Secondary reaction. About 36 hours after the first skin test of C $19 \mathrm{~K}$, erythema nodosum developed on both legs. These lesions persisted for $\mathbf{4 8}$ hours and then became purple and scaled. As no additional lesions appeared, the skin test was repeated after a few days on the opposite arm. The evolution of the lesions on the legs was observed with great care. The sequence of events following injection was as follows.

24 hours : indurated area felt on lower third of left leg, nothing seen.

36 hours : one large and two small pink, tender, nodular lesions on medial, lower third of left leg.

48 hours : new lesions appeared on middle third of both legs and on lower third of right leg. Old lesions more pronounced.

60 hours : new lesions on knees and just above knees (almost symmetrical).

72 hours: induration more marked, color fading.

84 hours: all lesions faded except those on lower left leg.

96 hours : lesions on lower third still palpable. Skin test subsided.

5th day: slight induration still present on lower third of legs.

6th day: legs returned to previous state.
Skin tests were then done with equivalent quantities of other bacterial proteins. The primary reactions were read as follows:

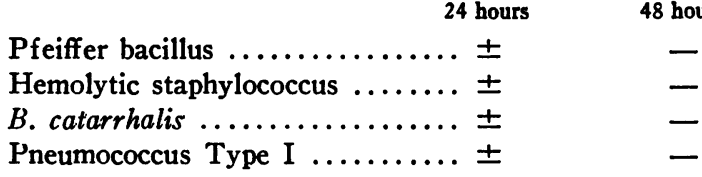

No secondary reactions followed these injections. One month later the patient was retested with $\mathrm{C} 19 \mathrm{~K}$ and again developed an intense local reaction, and a rise in temperature to $104^{\circ} \mathrm{F}$. However, no nodules appeared on the legs after this injection. The sites of previous cutaneous tests did not flare up at any time.

It was not possible in this first patient to determine whether the artificially induced lesions represented new nodules or a recrudescence of old nodules. In the second patient the induced nodules appeared to arise at new sites.

\section{Evelyn S., History Number 480647}

This patient was also an 8 year old girl who was admitted with erythema nodosum of 1 week's duration on both legs anteriorly and both arms posteriorly, symmetrical in distribution. Like the first patient she had had no frank rheumatic manifestations. Laboratory tests were negative except for leukocytosis of 16,000 , blood sedimentation rate of $86 \mathrm{~mm}$. in 1 hour and antistreptolysin titer of 500 units on repeated determination. She gave a positive skin reaction only to the nucleoprotein fraction of $\mathrm{C} 19 \mathrm{~K}$. The primary lesion measured 11.5 $\mathrm{cm} . \times 5.5 \mathrm{~cm}$., 24 hours after injection. Thirty-six hours after the skin test she developed a nodule on each leg in an area which appeared not to have been involved previously. These nodules began to fade after $\mathbf{4 8}$ hours.

\section{DISCUSSION}

These twelve patients with erythema nodosum developed a severe inflammatory reaction following the intracutaneous injection of hemolytic streptococcus nucleoprotein, at a time when there was a high titer of antistreptolysin in the circulation. The intense local reaction was similar to that seen in other patients who have recently had hemolytic streptococcus infection. However, shortly after the appearance of intense inflammation at the site of the intracutaneous test, six of these children developed a recrudescence of erythema nodosum in the previously affected parts. This response was not elicited unless the local inflammatory reaction was severe. It did not occur in control patients without erythema nodosum. The capacity of the involved extremities to de- 
velop erythema nodosum persisted for only a few weeks, at the end of which time an almost identical local reaction had no secondary effect. The evolution of the induced lesions and their relationship in time to the primary skin reaction showed a striking similarity in these six individuals.

Ernberg (3) observed a similar sequence of events in five tuberculous patients with subsiding erythema nodosum. Old tuberculin injected intracutaneously 6 to 14 days after the subsidence of the spontaneous erythema gave rise to intense local reactions which were followed by fresh efflorescences of nodular lesions in the same areas as had been involved previously. His findings were substantiated by Collis (4) who suggested that erythema nodosum is " produced by a soluble break-down product of certain organisms acting on already hypersensitive tissues."

The mechanism underlying the evolution of erythema nodosum is unknown. The circumstances under which the experimental induction of these lesions was possible suggest the following hypothesis. In the course of certain infections, symmetrical areas of the body become conditioned for a few weeks. Intense localized inflammation, presumably the result of specific antigenantibody reaction, liberates some substance into the circulation. This substance induces non-specific nodular lesions in the conditioned zones at a distance from the localized inflammatory reac- tion. This hypothesis is consistent with Topley's (5) conception of "the secondary effects of primary cellular reactions."

\section{SUMMARY}

The intracutaneous injection of the appropriate antigen in a patient with subsiding erythema nodosum is regularly followed by an intense inflammatory reaction at the site of injection.

The development of this local reaction was followed in half of the subjects tested by a recrudescence of erythema nodosum in the areas recently affected.

The capacity of the involved extremities to develop erythema nodosum persisted for only a few weeks.

A possible relation between the induction of erythema nodosum and an antigen-antibody reaction is discussed.

\section{BIBLIOGRAPHY}

1. Edström, G., Febris Rheumatica. Berlingska Boktryckeriet, Lund, 1935.

2. Coburn, A. F., The Factor of Infection in the Rheumatic State. Williams \& Wilkins Co., Baltimore, 1931.

3. Ernberg, H., Das Erythema nodosum, seine Natur und seine Bedeutung. Jahrb. f. Kinderh., 1921, 95, 1.

4. Collis, W. R. F., A new conception of the aetiology of erythema nodosum. Quart. J. Med., 1932, n. s. $1,141$.

5. Topley, W. W. C., An Outline of Immunity, William Wood \& Co., Baltimore, 1933, p. 220. 